Abstracta Iranica Abstracta Iranica

Revue bibliographique pour le domaine irano-aryen

Volume 27 | 2006

Comptes rendus des publications de 2004

\title{
« Long-Term Cross-Cultural Relations and State Formation in Transcaucasian Iberia. An Annaliste Perspective ». ANES 41, (2004), pp. 108-119.
}

\section{Rémy Boucharlat}

\section{OpenEdition}

1 Journals

\section{Édition électronique}

URL : http://journals.openedition.org/abstractairanica/5754

DOI : 10.4000/abstractairanica.5754

ISSN : 1961-960X

Éditeur :

CNRS (UMR 7528 Mondes iraniens et indiens), Éditions de l'IFRI

\section{Édition imprimée}

Date de publication : 15 mai 2006

ISSN : 0240-8910

Référence électronique

Rémy Boucharlat, « « Long-Term Cross-Cultural Relations and State Formation in Transcaucasian Iberia. An Annaliste Perspective ». ANES 41, (2004), pp. 108-119. », Abstracta Iranica [En ligne], Volume 27 | 2006, document 95, mis en ligne le 02 janvier 2007, consulté le 25 septembre 2020. URL : http:// journals.openedition.org/abstractairanica/5754 ; DOI : https://doi.org/10.4000/abstractairanica.5754

Ce document a été généré automatiquement le 25 septembre 2020.

Tous droits réservés 
« Long-Term Cross-Cultural Relations and State Formation in Transcaucasian Iberia. An Annaliste Perspective ». ANES 41, (2004), pp. 108-119.

\section{Rémy Boucharlat}

1 Si l'influence perse est indéniable en Géorgie d'époque achéménide (langue, religion architecture et décoration, art mobilier) les modalités de cette pénétration et, parallèlement, la définition de la culture locale contemporaine ont été peu scrutées, selon l'A. Pour lui, c'est un lent processus qui implique de connaître les antécédents locaux : une relation forte entre les élites et les Perses, les élites poursuivant cette culture ouverte qui aboutira à l'émergence du royaume d'Ibérie, plus tard que ne le suppose la tradition géorgienne après la chute des Séleucides. En bref, se situant dans la longue durée (l'approche des Annales dit l'A.), sa démarche ne nie pas le rôle de catalyseur qu'a joué l'empire perse, tandis que le contrôle des Séleucides apparaît peu important.

\section{INDEX}

Thèmes : 3.2.1. Elam 
AUTEURS

RÉMY BOUCHARLAT

IFRI-CNRS - Téhéran-Lyon 